\title{
Evidência dos covenants nas emissões de debêntures brasileiras
}

Os covenants têm como objetivo reduzir o risco relacionado à incerteza quanto à futura capacidade de pagamento da dívida e assegurar os direitos do debenturista Assim, este trabalho tem por objetivo identificar as cláusulas mais presentes nas emissões de debêntures e em paralelo evidenciar como os covenants podem estar relacionados com os setores das empresas emissoras de debêntures e seu nível de governança corporativa e o volume da emissão. Para este fim, recorreu-se as técnicas estatísticas descritiva e tabelas de frequência cruzada. Os dados foram coletados a partir dos formulários de referência das empresas que emitiram debêntures entre 2010 e 2018. Foram identificados 220 títulos para o período em análise e se percebe que quase não existe diferença entre os tipos de garantias adotados para diferentes volumes de captação de recursos; que as empresas do setor de transporte e energia elétrica se destacam como aquelas que mais adotam covenants de pagamento em suas emissões e que as empresas do novo mercado são aquelas mais dispuseram de cláusulas restritivas relacionadas ao pagamento. Os covenants de Dívida Líquida sobre EBITDA e Dívida sobre EBITDA, EBITDA sobre Despesa Financeira são os mais presentes. Estes somados representam 45\% das cláusulas restritivas presentes nas emissões. A categoria de covenant mais presente é aquele referente aos pagamentos. Isto permite inferir que esta categoria pode se configurar como a mais relevante no tocante a assimetria informacional e desempenho da organização para honrar com o compromisso junto aos debenturistas. Isto permite inferir que as empresas emissoras pretendem informar ao mercado que as condições de cumprimento das obrigações financeiras são as mais apropriadas para indicar sua capacidade de honrar com compromisso junto ao debenturista.

Palavras-chave: Mercado de crédito; Debentures; Covenants.

\section{Evidence of covenants in Brazilian debenture issues}

The covenants aim to reduce the risk related to uncertainty regarding the future capacity to pay the debt and to guarantee the debenture holder's rights. Thus, this paper aims to identify the most common clauses in the issuance of debentures and, in parallel, to show how the covenants may be related to the sectors of the debenture issuing companies and their level of corporate governance and the volume of the issue. For this purpose, descriptive statistical techniques and crossfrequency tables were used. The data were collected from the reference forms of the companies that issued debentures between 2010 and 2018 . 220 securities were identified for the period under analysis and it is clear that there is almost no difference between the types of guarantees adopted for different fundraising volumes. That companies in the transport and electric power sector stand out as those that most adopt payment covenants in their emissions and that companies in the new market are those that have the most restrictive payment-related clauses. The covenants of Net Debt on EBITDA and Debt on EBITDA, EBITDA on Financia Expenses are the most present. These added up represent $45 \%$ of the restrictive clauses present in the issues. The most prevalent covenant category is that of payments. This allows us to infer that this category can be configured as the most relevant in terms of informational asymmetry and performance of the organization to honor the commitment with the debenture holders. This allows us to infer that the issuing companies intend to inform the market that the conditions of compliance with the financial obligations are the most appropriate to indicate their ability to honor the debenture holder with commitment.

Keywords: Credit market; Debentures; Covenants.

Topic: Finanças Empresariais

Reviewed anonymously in the process of blind peer.
Received: 04/12/2019

Approved: 12/01/2020
Kliver Lamarthine Alves Confessor (iD Universidade Federal de Pernambuco, Brasil http://lattes.cnpq.br/6761541646953979 http://orcid.org/0000-0002-6972-634X adm.kliver@gmail.com

Joséte Florencio dos Santos (iD

Universidade Federal de Pernambuco, Brasil http://lattes.cnpq.br/5657418279526928 http://orcid.org/0000-0002-5366-2548 js@@ufpe.br

Gabriel Martins Santos (iD

Universidade Federal de Pernambuco, Brasil http://lattes.cnpq.br/9348294994654589 http://orcid.org/0000-0002-7309-391X gabriel.martinssantos99@gmail.com

\section{Referencing this:}

CONFESSOR, K. L. A.; SANTOS, J. F.; SANTOS, G. M.. Evidência dos covenants nas emissões de debêntures brasileiras. Revista Brasileira de Administração Científica, v.11, n.1, p.1-15, 2020. DOI: http://doi.org/10.6008/CBPC2179-684X.2020.001.0001 


\section{INTRODUÇÃO}

No processo de financiamento, uma das fontes de recursos das empresas é a emissão de títulos no mercado de crédito. Segundo Beiruth et al. (2016) o financiamento das empresas com capital de terceiros é de suma importância para no desenvolvimento de suas atividades. Nesse interim a emissão de debêntures ocupa lugar de importância nos últimos anos, permitindo inferir que o mercado de títulos corporativos passou a ser uma importante fonte de recursos para as organizações.

A CVM (2011) justifica o volume dessa modalidade de investimento negociadas em 2013 em função do ajuste na legislação, a lei n 12.431, que instituiu uma série de reformas na Lei das Sociedades por Ações, com vistas, a flexibilização do processo de emissão desses títulos e melhoria do ambiente de negociação nos mercados secundários, uma vez que podem ser ajustadas condições como prazo, fluxo de amortização, de pagamento de juros, garantias e remuneração.

Debênture é definida pela Lei $n^{\circ}$ 6.385/76 como um valor mobiliário representativo de um contrato mútuo, registrados no Sistema Nacional de Debêntures (SND), da CETIP2 e regulamentados pela Comissão de Valores Mobiliários (CVM), em geral de longo prazo, entre o emissor e os debenturistas. São, portanto, títulos de dívida emitidos por sociedade anônima de capital aberto ou fechado, sendo considerados uma fonte de financiamento utilizada pelas empresas para captação de recursos, especialmente para investimentos que conferem aos seus detentores diretos de crédito, pois geralmente possuem prazos, garantias, e benefícios fiscais diferentes dos empréstimos bancários, possibilitando às empresas financiar seus projetos e operações.

De acordo com o estabelecido na Lei № 6.404, de 1976, a emissão das debêntures poderá ser efetuada com ou sem garantias, essas garantias têm como objetivo assegurar aos debenturistas o cumprimento da obrigação do principal, podendo ser cumulativas e substituídas desde que registrado na escritura de emissão. Os principais tipos de garantias existentes são garantia real, flutuante, quirografárias, subordinadas, e as garantias acessórias.

Existem outras garantias que são usadas de forma complementar, são as (1) fidejussória, que correspondem a fiança ou aval prestados, geralmente por acionistas controladores da emissora ou uma das empresas integrantes do seu grupo; (2) covenants, que denominam um conjunto de obrigações que a companhia emissora assume com o objetivo de assegurar, direta ou indiretamente, o cumprimento da obrigação principal, ou seja, o pagamento da dívida perante ao debenturista.

Segundo Smith et al. (1979) os covenants possuem a função de mitigar os conflitos existentes na relação entre tomadores de empréstimo (empresas) e credores, reduzindo os custos financeiros da operação e aumentando o valor total da empresa. Para uma melhor compreensão dos dessas cláusulas restritivas. Para Watts et al. (1986; 1990), existe uma forte relação entre os covenants e as informações relacionadas ao setor contábil, uma vez que os covenants são frequentemente escritos em termos de números contábeis. Nesse sentido, Mather et al. (2006) apresentaram duas classificações para estas restrições, dividindo-os em dois grandes grupos: 1) covenants contábeis e 2) não-contábeis. Nesse sentido, Beiruth et al. (2016) citam que o 
estudo destes limites no campo das ciências contábeis ganha relevância devido ao fato destas cláusulas estarem presentes em boas partes dos contratos por meio de indicadores da área contábil.

O covenant vem sendo utilizado em muitos casos brasileiros principalmente no que diz respeito à emissão de debêntures, segundo Neis et al. (2016). Nestes casos, em virtude do grande valor de algumas operações, estas cláusulas assumem o papel de mitigador de risco, passando a ser relevante entender a forma pela qual o mercado de crédito brasileiro identifica, classifica e interpreta tais informações, a fim de que o investidor possa mensurar o risco de alocar seu capital em determinada debênture. Nesse sentido a presente pesquisa realizou um mapeamento dos covenants adotados pelas empresas emissoras de debêntures entre 2010 e 2018.

\section{REVISÃO TEÓRICA}

\section{Título de longo prazo privado: as debêntures}

Debênture é um valor mobiliário representativo de um contrato de mútuo, em geral de longo prazo, entre o emissor e os debenturistas. São, portanto, títulos de dívida emitidos por sociedade anônima de capital aberto ou fechado, que conferem aos seus detentores direitos de crédito e, assim, consistem em um instrumento de captação de recursos no mercado de capitais que possibilita às empresas financiar seus projetos e operações, segundo consta no Sistema Nacional de Debêntures - SND (2018).

Nessa perspectiva, pode-se dizer que o detentor de debêntures, ao subscrevê-la, torna-se credor da companhia emitente e passa a ser conhecido como debenturista. Neste processo, o investidor disponibiliza os recursos correspondente ao valor dos títulos emitidos à companhia emissora, com a expectativa de receber juros periódicos acrescidos do pagamento do principal investido, durante o prazo contratado e conforme as condições definidas pela escritura de emissão.

As debêntures são definidas pela no Lei 6.385/76, como valores mobiliários, registrados no SND, da CETIP2 e regulamentados pela Comissão de Valores Mobiliários (CVM), órgão responsável pela fiscalização do mercado de valores mobiliários. Esses títulos são considerados uma fonte de financiamento utilizada pelas empresas para captação de recursos, especialmente para investimentos, pois geralmente possuem prazos, garantias e benefícios fiscais diferentes dos empréstimos bancários. São também de fácil adequação aos fluxos de pagamento e às condições de geração de caixa por parte das empresas (GIACOMINI et al., 2013), o que por sua vez contribui para que esses títulos ocupem a condição de valor mobiliário mais utilizado no âmbito do mercado financeiro (ANBIMA, 2014).

A Figura 1 sistematiza o mercado de debêntures no qual o processo de emissão se dá por distribuição pública ou privada. A captação de recursos no mercado de capitais, por meio de emissão de debêntures, representa a emissão de um título da dívida por parte da empresa emissora e que ficará disponível ao mercado. O Agente fiduciário é o responsável pela proteção e defesa dos interesses da comunhão dos debenturistas e da realização de seus créditos, bem como na representação dos debenturistas em processo de falência e promover a execução de eventuais garantias em prol do credor. Em seguida, a empresa poderá 
registrar as debêntures no Sistema Nacional de Distribuição de Títulos - SND e no Sistema Nacional de Debêntures - SND da Central de Custódia e de Liquidação Financeira de Títulos (Cetip) a fim de que seus títulos possam ser negociados.

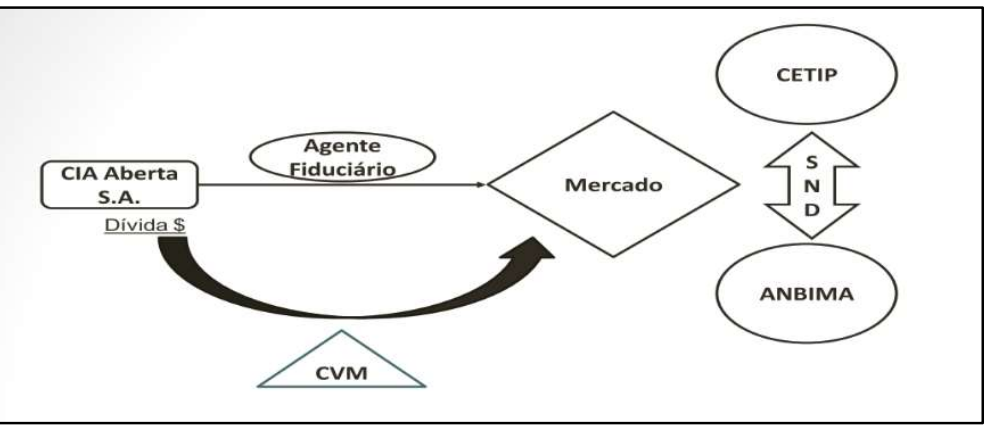

Figura 1: Configuração do Mercado de debêntures. Fonte: Coelho et al. (2017).

Diante do exposto convém apresentar algumas características que delimitam as debêntures, como por exemplo a sua natureza quanto à origem e emissão, classe, remuneração e garantias. No que se refere à emissão de debêntures ocorrem duas classificações: públicas e privadas, que variam conforme o perfil de investidor a quem são destinadas. As emissões privadas são voltadas a um grupo restrito de investidores e seu processo de emissão não exige o registro na CVM. Já as emissões públicas são direcionadas ao público em geral e somente podem ser realizadas por companhias abertas e com registro na Comissão de Valores Mobiliários.

As emissões públicas são vinculadas a um Programa de Distribuição de Valores Mobiliários e estão amparadas pela Instrução CVM no 400, de 29/12/2003, na qual determina que a companhia esteja sempre assessorada por uma ou mais instituições intermediárias, quais serão responsáveis pelas informações, verificações, distribuição, e, em alguns casos, pela estruturação da debênture. Outro requisito para as emissões públicas de debêntures é a contratação de agente fiduciário, que deve representar os interesses dos debenturistas junto à companhia emissora e são responsáveis por verificar o cumprimento das condições pactuadas na escritura e pela elaboração de relatórios de acompanhamento.

Diante disso, tem-se que as debêntures negociadas pela primeira vez serão emitidas no mercado primário, que se refere à distribuição pública de debêntures no mercado pela sua emissora, e só poderá ocorrer com a intermediação de instituições financeiras devidamente cadastradas no sistema de distribuição de valores mobiliários. Mercado secundário, por sua vez, se refere ao ambiente onde ocorrem as negociações de debêntures já emitidas, isto é, já lançadas no mercado primário. Neste mercado os agentes econômicos têm a oportunidade de trocar posições, ou seja, vender títulos em carteira antes de seu vencimento.

Quanto à forma, as debêntures podem ser classificadas em nominativas ou escriturais. Para as primeiras, a companhia emite a debênture em nome do investidor inicial e o registro e o controle das transferências são realizados pela companhia emissora em livro próprio de registro de debêntures nominativas. Nesse caso, é opcional a contratação de serviços de escrituração e guarda dos livros de registros da emissão e das transferências do ativo. Já as debêntures escriturais, apesar de também serem nominativas, não exigem a emissão de certificado. Seus valores ficam mantidos em contas de custódia em nome de seus 
As debêntures também podem ser classificadas quanto à classe. Neste caso existem três categorias: as debêntures simples, que não conferem direito de conversão em ações; as debêntures conversíveis, que permitem a conversão em ações da companhia emissora; e as debêntures permutáveis, que permitem a troca do título por ações de outras companhias descritas na escritura da emissão, contendo, portanto, uma opção de compra embutida de ações de outras companhias.

Na remuneração da debênture se observa um prêmio exigido pelo investidor composto de duas faixas de remuneração: a primeira delas reflete a taxa de juros básica da economia e a segunda reflete a taxa de juros adicional que as instituições emissoras de dívidas se propõem a pagar ao investidor pelos riscos adicionais em comparação com os ativos livres de risco.

O investidor pode alocar seus recursos comprando títulos de dívida do governo, que são conhecidos com risk free, ou seja, livres de riscos. A remuneração destes títulos é formada de uma taxa de juros real e a incorporação de um indicador de inflação. Enquanto a esta segunda faixa de remuneração, paga ao investidor na emissão de títulos privados, é chamada de spread. Portanto, a valorização adicional do título compreende o resultado adicional à taxa livre de risco, que é chamada de yield spread.

Portanto, a classificações das debêntures quanto à remuneração possui duas alternativas: juros fixos ou variáveis. No Brasil, a forma mais comum é baseada em taxas prefixadas, sejam elas: taxas de juros pósfixada (DI, Selic); Taxa Referencial (TR); Taxa de Longo Prazo (TLP); Taxa Básica Financeira (TBF); atualização monetária (índice de preços) e variação cambial. Convém destacar que em uma mesma emissão de debêntures pode ocorrer mais de uma forma de remuneração, que é a denominada remuneração mista.

E no tocante ao vencimento, as emissões de debêntures se dividem entre aquelas que possui um prazo determinado e as que são perpetuas. Neste último caso, o vencimento fica condicionado às situações de inadimplemento de pagamento de juros, dissolução da companhia e outros eventos, conforme forem mencionados no prospecto da emissão.

De acordo com o estabelecido na Lei no 6.404/76, a emissão das debêntures poderá ser efetuada com ou sem garantias. Essas garantias têm como objetivo assegurar aos debenturistas o cumprimento da obrigação do principal, podendo ser cumulativas e substituídas, desde que registrado na escritura de emissão. Os principais tipos de garantias existentes são: garantia real, flutuante, quirografárias, subordinadas, e as garantias acessórias.

Existem outras garantias que são usadas de forma complementar. São as garantias (1) fidejussória, que correspondem à fiança ou aval prestados, geralmente por acionistas controladores da emissora ou uma das empresas integrantes do seu grupo; (2) covenants, que denominam um conjunto de obrigações que a companhia emissora assume com o objetivo de assegurar, direta ou indiretamente, o cumprimento da obrigação principal, ou seja, o pagamento da dívida perante ao debenturista.

A necessidade de proteção tanto do emissor quanto do debenturista contra as incertezas do mercado brasileiro e a possibilidade de adicionar valor às debêntures, motivaram a criação de títulos com cláusulas contratuais extremamente sofisticadas e criativas, por exemplo, a presença dos covenants. Nesse sentido, a próxima seção trata sobre os conceitos e operacionalização dos covenants. 
Além do exposto, convém destacar que para que os investidores possam negociar debêntures, é necessário que elas sejam custodiadas em uma das centrais de liquidação e custódia credenciadas pela CVM. Essas centrais são também responsáveis pela compensação e pela liquidação física e financeira das operações. Esse controle é feito pelo SND e administrado pela CETIP por meio de um sistema eletrônico em que são registradas as negociações do mercado secundário de debêntures.

O Sistema Nacional de Debêntures foi concebido para atuar dentro da CETIP, com a missão de criar as condições para o desenvolvimento do mercado brasileiro. Seu principal objetivo é apoiar o mercado de processo de distribuição primária e negociação secundária de debêntures, por meio de um sistema eletrônico em que os investidores podem acompanhar diariamente todas as características e informações sobre as debêntures registradas, como, por exemplo, os preços de curva dos ativos, denominados PU Par, ou PU histórico, que representa o valor da debênture em determinada data. Também são divulgadas no SND as informações dos preços observados nas negociações no mercado secundário. Por fim, ainda são divulgados no SND os preços e taxas de referência para debêntures, calculados pela ANBIMA (COELHO et al., 2017).

\section{Cláusulas contratuais dos títulos privados}

No mercado de crédito são comuns operações de financiamentos a partir de emissões de debêntures, cujo objetivo das empresas é obter o capital necessário para a realização de seus negócios e o dos credores é garantir o recebimento dos recursos emprestados acrescidos dos juros advindos da operação financeira. Estas operações estão sujeitas a riscos e para minimizá-los se verifica a presença de condições restritivas contratuais em algumas emissões de debêntures, chamadas covenants, além dos outros tipos de garantias, conforme exposto no quadro 2 .

O termo covenant, original do inglês, tem como significado algo similar às noções de convenção, pacto, convênio, cláusula de contrato, de forma que pode ser entendido como cláusula pactuada entre o agente financiador e o tomador de crédito, de modo a resguardar o credor em situações de possível inadimplência ou de eventuais modificações estruturais por parte da tomadora dos recursos. Configura-se, portanto, como mecanismo de proteção do credor em operações creditícias.

Para Assaf Neto (2010), a qualidade das decisões tomadas é fundamental para a continuidade de qualquer negócio, independentemente do nível organizacional. A Contabilidade, por sua vez, auxilia estas decisões disponibilizando dados e informações retiradas por meio do comportamento do mercado e desempenho da organização, podendo ser analisados através dos indicadores financeiros.

Diante do exposto e conforme preconizado pela teoria da agência (JENSEN et al., 1976), verifica-se que os acionistas podem transferir (apropriar-se) das riquezas de debenturista de diversas maneiras, como, por exemplo, podem pagar a si mesmos os dividendos, ou podem recomprar ações, ou ainda investir em projetos de alto risco por meio da emissão adicional de dívida.

Para contornar essa situação os debenturistas se apropriam de cláusulas restritivas. Como mencionado por Jensen et al. (1976) e Smith et al. (1979), as cláusulas de dívida podem reduzir o custo do risco moral associado a financiamentos de dívidas e, portanto, diminuir as interferências da administração 
no valor da dívida. Além disso, as cláusulas permitem que credores antecipem o vencimento caso o emitente, por exemplo, não siga regras preestabelecidas.

No entanto, há um equilíbrio no estabelecimento de cláusulas. Pelo lado dos debenturistas, custos associados com as cláusulas incluem monitoramento e a possibilidade de renegociação do contrato da dívida. Pelo lado da empresa tomadora, as cláusulas podem levar a decisões financeiras menos racionais e a investimentos menores. As cláusulas também aumentam a necessidade de uma recontratação. Se a qualidade do crédito se deteriorar, os credores podem querer renegociar os termos do contrato, isto é, impor taxas de juros mais altas, mais garantias, ou mais restrições nas atividades futuras. Da mesma forma, se a qualidade do crédito melhorar, os tomadores vão querer renegociar os termos da dívida com os atuais credores, ou fazer uma operação de refinanciamento com os novos (SAITO et al., 2007).

Para Borges (1999), os covenants constituem cláusulas contratuais que impõem restrições e obrigações aos devedores servindo como uma espécie de garantia adicional, estabelecendo compromissos e limites à empresa tomadora de recursos para assegurar a capacidade de pagamento, dessa forma, além da possiblidade de contribuir para reduzir o risco de inadimplência da dívida, estas cláusulas contratuais podem minimizam os conflitos de agência entre a empresa e o credor, uma vez que, de acordo com Beiruth et al. (2016) é possível utilizar dados contábeis para restringir ações dos administradores e acionistas que são contra aos interesses dos credores. Nesse sentido, Christensen et al. (2012) ressaltam a importância dos covenants nos contratos de crédito pois podem ser utilizados como meio de acompanhar a saúde financeira da empresa provisionando um possível inadimplemento.

Segundo Perin et al. (2015), a utilização do covenant no Brasil é recente, embora cada vez mais presente em negócios bancários. Geralmente o covenant é utilizado como uma condição a fim de minimizar o risco de inadimplemento. De tal forma que o descumprimento de alguma cláusula implicaria uma prerrogativa de o credor antecipar o vencimento da debênture.

O covenant vem sendo utilizado em muitos casos brasileiros, principalmente no que diz respeito à emissão de debêntures, segundo Perim et al. (2015) e Neis et al. (2016). Nestes casos, em virtude do grande valor de algumas operações, o covenant assume o papel de mitigador de risco, passando a ser relevante entender a forma pela qual o mercado de crédito brasileiro identifica, classifica e interpreta tais cláusulas, a fim de que o investidor possa mensurar o risco de alocar seu capital em determinada debênture.

Assim, pode-se dizer que o covenant representa uma alternativa de acompanhar a saúde da empresa, impondo obrigações a serem respeitadas no decorrer do prazo do financiamento a fim trazer informações que a empresa terá condições de arcar com o adimplemento ao fim do prazo estipulado. Nesse sentido, resgata-se os resultados de Smith et al. (1979) ao testar se os covenants são inseridos nos contratos de empréstimos com a função de mitigar os conflitos existentes na relação financiador-acionista, reduzindo os custos financeiros da operação e aumentando o valor total da empresa. Esses autores foram os primeiros a analisar os efeitos das cláusulas restritivas nos contratos, examinando a forma pela qual os contratos foram escritos para reduzir o conflito entre acionistas e credores e concluíram que os covenants reduzem o conflito de agência. 
Ainda em relação à expectativa de discutir como o mercado de crédito identifica, classifica e interpreta tais cláusulas, Smith et al. (1979) identificaram quatro principais tipos de restrições contratuais: 1) cláusulas de ativo; 2) cláusulas de dividendos; 3) cláusulas de financiamento; 4) cláusulas sobre o pagamento. Os autores mostraram que estas cláusulas têm o poder de reduzir em parte a assimetria de informações e conflitos de interesses existentes entre as partes.

Os covenants assumem importante papel nos contratos de dívidas uma vez que buscam muito mais a credibilidade do devedor, agindo diferente das garantias reais ou pessoais disponíveis no mercado, por exemplo, as garantias hipotecárias, pignoratícias ou fidejussórias. A seguir serão apresentados os principais convenants encontrados na literatura, bem como os estudos desenvolvidos sobre essa temática

\section{METODOLOGIA}

A abordagem utilizada foi quantitativa uma vez que as análises seguiram os elementos da estatística descritiva como soma, porcentagem, distribuição de frequências, gráficos e tabelas a fim de realizar inferências sobre a população do objeto de estudo da amostra estudada. A população da pesquisa é formada por todas as empresas de capital aberto brasileiras que estavam atuando no mercado de capitais entre 2010 a 2018, com registro na Comissão de Valores Mobiliários (CVM). Para a classificação e identificação dos covenants foram considerados apenas as emissões primárias. Adicionalmente os covenants foram classificados de acordo com quatro principais tipos de restrições contratuais: 1) Cláusulas de ativos; 2) Cláusulas de dividendos; 3) Cláusulas de financiamento; 4) Cláusulas sobre pagamentos, a fim de corroborar com os estudos de Smith et al. (1979), a partir da categorização das cláusulas restritivas e identificando qual é o principal tipo de restrição contratual presente nas emissões das debêntures.

O primeiro passo da coleta dos dados foi verificar se a empresa havia emitido debêntures durante o período de 2010 a 2018 a partir da análise do item f dos formulários de referência, na qual informa os níveis de endividamento e as características de tais dívidas. A partir da análise deste tópico específico, foi possível identificar as garantias adotadas pelas empresas, como por exemplo, limites de endividamento e contratação de novas dívidas, à distribuição de dividendos, à alienação de ativos, à emissão de novos valores mobiliários e à alienação de controle societário. De tal forma que o levantamento de todas estas informações permitiu mapear os covenants nas respectivas emissões de debêntures.

Em seguida, a partir dos dados extraídos do Economatica, foi possível construir o banco de dados de emissões de debêntures relacionando os covenants com o volume de emissão e vencimento, bem como o setor de atuação da empresa e a sua classificação do Nível de Governança Corporativa. Quando necessário para obter estas informações complementares, recorreu-se à consulta no site da Bolsa, Brasil e Balcão.

Durante o mapeamento dos covenants foi possível identificar as cláusulas restritivas mais presentes nas debêntures a agrupá-las conforme suas características e categorias propostas por Smith et al. (1979). Em seguida, realizou-se o cruzamento das informações com o nível de governança corporativa das empresas que emitiram debêntures para o período analisado, bem como os setores de atuação e o volume da emissão por meio de distribuição de frequências e tabelas descritivas. Desta forma foi possível identificar as empresas 
brasileiras que emitiram debêntures no período de 2010 a 2018; classificar os covenants presentes nas emissões das debêntures e evidenciar os covenants mais usados.

\section{RESULTADOS E DISCUSSÃO}

Após a análise de cada formulário de referência para as empresas listadas na B3 durante o período de 2010 a 2018, que haviam emitido debêntures, independentes de terem mencionado a presença de covenants, identificou-se 220 emissões de debêntures, para 154 empresas que compõe a amostra. A distribuição de frequência destas emissões está indicada na Tabela 1. Convém destacar que deste total apenas em 32 emissões foram omissas em relação a presença das cláusulas restritivas, conforme analisado no formulário de referência das empresas.

Tabela 1: Distribuição de frequência das emissões de debêntures para o período de 2010 a 2018.

\begin{tabular}{|l|l|l|}
\hline \multicolumn{1}{|c|}{ Ano da emissão } & \multicolumn{1}{|c|}{ Quantidade de emissões } & \multicolumn{1}{|c|}{ Frequência relativa das emissões } \\
\hline 2017 & 51 & $23,181 \%$ \\
\hline 2018 & 34 & $15,459 \%$ \\
\hline 2012 & 27 & $12,272 \%$ \\
\hline 2013 & 25 & $11,363 \%$ \\
\hline 2016 & 22 & $10 \%$ \\
\hline 2015 & 19 & $8,636 \%$ \\
\hline 2014 & 19 & $8,636 \%$ \\
\hline 2011 & 18 & $8,181 \%$ \\
\hline 2010 & 5 & $2,272 \%$ \\
\hline TOTAL & $\mathbf{2 2 0}$ & $\mathbf{1 0 0 \%}$ \\
\hline
\end{tabular}

Percebe-se que as empresas emitiram títulos em grande quantidade nos anos de 2012 e 2013 em virtude da busca de recursos financeiros, devido principalmente às crises e tensões do cenário mundial, uma vez que, conforme a teoria da estrutura de capital: a captação de recursos por meio de capital de terceiros possui mais aspectos positivos do que a utilização de capital próprio, sobretudo quando obtido por meio da emissão de debêntures, dado as taxas de juros e prazos maiores para pagamento.

Ademais, nota-se também um aumento no número de emissões no período entre 2016 e 2018, devido ao fim do período de recessão da economia brasileira, a partir do registro de quedas sucessivas na inflação e na taxa básica de juros. Possibilitando, assim, um cenário propício para a emissão de novos títulos no mercado de crédito. A distribuição de covenants e suas respectivas frequências do período de 2010 a 2018 é apresentada na Tabela 2. De forma que nos permite perceber grande variedade destas clausulas nos contratos de dívida das empresas, totalizando 71 tipos.

Nota-se que existem uma grande diversidade de covenants utilizados no mercado brasileiro, porém com baixa incidência, como por exemplo, garantias que envolvem cartão de crédito; imóveis; frota; restrição de alienação de ativos e outros mais que foram agrupados em garantias diversas. Durante o processo de análise dos formulários de referente pode-se inferir que estas clausulas peculiares são definidas, muitas vezes, para atender à exigência de um debenturista - BNDES, por exemplo. Ademais, convém destacar que estas garantias de baixa incidência, não foram utilizadas isoladamente.

$\mathrm{Na}$ expectativa de identificar quais covenants foram mais citados nas emissões de debêntures, por meio de contagem e observação da frequência, foi possível perceber 71 tipos de cláusulas nas emissões 
analisadas. Destes, 32 tipos foram presentes apenas uma vez e 12 tipos de covenants estavam presentes somente duas vezes, indicado na tabela 2 como 'Garantias diversas'. As cláusulas restritivas mais representativas foram: Dívida sobre EBITDA; Dívida Liquida sobre EBITDA e EBITDA sobre Despesa Financeira.

Tabela 2: Distribuição de frequência dos covenants nas emissões de debêntures para o período de 2010 a 2018.

\begin{tabular}{|c|c|c|}
\hline Covenants financeiros & $\begin{array}{c}\text { Frequência } \\
\text { Bruta dos } \\
\text { Tipos de } \\
\text { Covenants }\end{array}$ & $\begin{array}{c}\text { Frequência } \\
\text { relativa dos } \\
\text { tipos } \\
\text { Covenants }\end{array}$ \\
\hline Dívida sobre EBITDA & 93 & $24 \%$ \\
\hline Garantias diversas & 56 & $14 \%$ \\
\hline Dívida Líquida sobre EBITDA & 52 & $13 \%$ \\
\hline EBITDA sobre Despesa Financeira & 52 & $8 \%$ \\
\hline Índice de Cobertura do Serviço da Dívida (ICSD) & 19 & $5 \%$ \\
\hline EBITDA Resultado Financeiro & 15 & $4 \%$ \\
\hline Restrição ao pagamento de dividendos & 12 & $3 \%$ \\
\hline Restrição a alienação de ativos & 11 & $3 \%$ \\
\hline EBITDA sobre Serviço da Dívida & 10 & $3 \%$ \\
\hline EBITDA & 18 & $3 \%$ \\
\hline Recebíveis + Receita a apropriar + Estoques sobre Dívida Líquida + Imóveis a Pagar + Custo a apropriar & 9 & $2 \%$ \\
\hline Cobertura de juros & 7 & $2 \%$ \\
\hline Patrimônio Líquido sobre Ativo Total & 6 & $2 \%$ \\
\hline Dívida Líquida + Imóveis a Pagar sobre Patrimônio Líquido & 8 & $1 \%$ \\
\hline Patrimônio Líquido sobre Passivo Total & 4 & $1 \%$ \\
\hline Dívida Líquida sobre Patrimônio Líquido & 7 & $1 \%$ \\
\hline Restrição em relação à contratação de novas dívidas & 3 & $1 \%$ \\
\hline Endividamento de curto prazo sobre Endividamento total & 3 & $1 \%$ \\
\hline Dívida Líquida sobre Frota Líquida & 3 & $1 \%$ \\
\hline Dívida - saldo de crédito sobre EBITDA & 3 & $1 \%$ \\
\hline TOTAL & 391 & $100 \%$ \\
\hline
\end{tabular}

Estes são fortes indicadores de desempenho e capacidade financeira de honrar as dívidas mediante o lucro gerado. Estes covenants, portanto, são aqueles mais utilizados para informar aos credores sobre a situação financeira da empresa para servirem de garantias face ao pagamento das debêntures. Ainda em relação a caracterização do covenants realizou-se a classificação das cláusulas conforme os critérios estabelecidos por Smith et al. (1979). A Tabela 3 indica quais dessas categorias foram mais presentes nas emissões de debêntures brasileiras para o período de 2010 a 2018.

Tabela 3: Distribuição de frequência dos covenants nas emissões de debêntures para o período de 2010 a 2018.

\begin{tabular}{|l|l|l|}
\hline \multicolumn{1}{|c|}{ Classificação dos covenants } & \multicolumn{1}{c|}{ Frequência Bruta } & Frequência relativa \\
\hline Cláusulas sobre pagamentos & 330 & $84 \%$ \\
\hline Cláusulas de ativos & 32 & $8 \%$ \\
\hline Cláusulas sobre dividendos & 15 & $4 \%$ \\
\hline Cláusulas sobre financiamento & 14 & $4 \%$ \\
\hline TOTAL & 391 & $\mathbf{1 0 0 \%}$ \\
\hline
\end{tabular}

Conforme pode-se observar, as cláusulas sobre pagamentos são as mais presentes nas emissões de debêntures. Isto pode ser justificado pelo fato de que estas clausulas possuem relação com a capacidade da empresa de gerar riqueza e de honrar com seus compromissos financeiros assumidos com os credores. A fim de compreender se existe um padrão de maior (menos) presença dos convenants em emissões de alto (baixo) volume, buscou separar as emissões de debêntures pela mediana do volume captado, sob a perspectiva de identificar o perfil dos convenants conforme o volume. Os resultados alcançados são apresentados na Tabela 4. 
Tabela 4: Distribuição de volume de debêntures para a quantidade de covenants presentes nas emissões de 2010 a 2018.

\begin{tabular}{|l|l|l|}
\hline \multicolumn{1}{|c|}{ Classificação do covenant } & \multicolumn{1}{c|}{ Classificação do volume } & Frequência Bruta \\
\hline Pagamentos & Alto & 172 \\
\hline Pagamentos & Baixo & 177 \\
\hline Ativo & Alto & 20 \\
\hline Ativo & Baixo & 19 \\
\hline Financiamento & Alto & 8 \\
\hline Financiamento & Baixo & 13 \\
\hline Dividendo & Alto & 10 \\
\hline Dividendo & Baixo & 10 \\
\hline
\end{tabular}

De acordo com Sheng et al. (2005) e Aguiar (2012) é espero que quanto maior o risco da emissão maior a necessidade de garantias, ou seja, quanto maior a volume da emissão maior a necessidade de covenants e provavelmente quanto mais covenants mais garantias haverá para o credor. No entanto, percebe-se que quase não existe diferença entre os tipos de garantias adotados para diferentes volumes de captação de recursos. O que dá suporte ao questionamento de que deve existir algum tipo de covenant mais relevante e por isso os demais covenants presentes no processo de emissão da debênture sejam irrelevantes.

Nesse interim, verifica-se a maior presença dos covenants presente na categoria de pagamento, representados por Dívida sobre EBITDA; Dívida Liquida sobre EBITDA e EBITDA sobre Despesa Financeira. Ante o exposto buscou compreender qual o comportamento dos covenants conforme a classificação setorial das empresas que emitiram debêntures. A quantidade de emissões de debêntures por setor de atuação é demonstrada na Tabela 5.

Tabela 5: Setor atuação das empresas emissoras de debêntures no período de 2010 e 2018.

\begin{tabular}{|l|l|}
\hline \multicolumn{1}{|c|}{ Setor de atuação } & \multicolumn{1}{|c|}{ Frequência Bruta } \\
\hline Energia elétrica & 122 \\
\hline Transporte & 64 \\
\hline Locadora de automóveis & 18 \\
\hline Extração de Petróleo e Gás & 16 \\
\hline Água, esgoto e outros sistemas & 15 \\
\hline Telecomunicações & 11 \\
\hline Construção & 10 \\
\hline Loja de departamentos & 8 \\
\hline Laboratório de exames médicos & 7 \\
\hline Locadora de imóveis & 7 \\
\hline Comércio & 6 \\
\hline Mineração de metais & 6 \\
\hline Educação & 5 \\
\hline Seguradora & 4 \\
\hline Administração de empresas e empreendimentos & 3 \\
\hline Escola de ensino superior & 3 \\
\hline Indústria de autopeças & 3 \\
\hline Serviços financeiros e seguros & 3 \\
\hline Indústria química & 2 \\
\hline Saúde & 2 \\
\hline Outros & 12 \\
\hline
\end{tabular}

No que concerne a compreensão do setor de atuação das empresas que mais emitiram debêntures, visualiza-se que o setor de Energia Elétrica é o mais representativo, com 122 emissões e em seguida os setores Locação de automóveis com 18 emissões e o setor de Água, esgoto e outros sistemas, com 15 emissões. Convém destacar que necessidade recorrente de expansão desses setores durante o período da 
análise e os benefícios de terem emitido debêntures incentivadas. Os setores que menos emitiram foi o de Bolsa de Valores e commodities, Indústria de roupas de tecido, Indústria manufatureira, Loja de artigos para saúde e cuidados pessoais, outras Indústrias de recreação, Serviço, Serviço de Armazenamento, Serviço de entregas e mensagens, Serviço de apoio às empresas, Serviço de engenharia e arquitetura e Tecelagem.

Isso se deve ao fato destas empresas terem graus de endividamento reduzidos, não necessitando captar tantos recursos com tanta frequência. Com os dados obtidos a partir da análise dos setores de atuação, relacionou-se os principais setores com as respectivas categorias dos covenants a fim de identificar se existe categorias de covenants específicos que se destacam na sua adoção em algum setor. Este resultado é apresentado na Tabela 6.

Tabela 6: Relação entre setores e atuação das empresas que detinham covenants por grupos de cláusulas de covenants para o período de 2010 a 2018.

\begin{tabular}{|c|c|c|c|c|c|}
\hline Setor de atuação & $\begin{array}{c}\text { Cláusulas sobre } \\
\text { Pagamentos }\end{array}$ & $\begin{array}{c}\text { Cláusulas sobre } \\
\text { Ativos }\end{array}$ & $\begin{array}{l}\text { Cláusulas sobre } \\
\text { Financiamento }\end{array}$ & $\begin{array}{c}\begin{array}{c}\text { Cláusulas sobre } \\
\text { dividendos }\end{array} \\
\end{array}$ & Total \\
\hline Água, esgoto e outros sistemas & 15 & 5 & 0 & 5 & 25 \\
\hline Comércio & 9 & 0 & 0 & 0 & 9 \\
\hline Construção & 19 & 0 & 0 & 0 & 19 \\
\hline Energia elétrica & 79 & 12 & 6 & 4 & 101 \\
\hline Escola de ensino superior & 6 & 1 & 1 & 0 & 8 \\
\hline Extração de Petróleo e gás & 5 & 0 & 6 & 0 & 11 \\
\hline Indústria de autopeças & 2 & 1 & 0 & 1 & 4 \\
\hline Indústria química & 4 & 0 & 2 & 2 & 8 \\
\hline Laboratório de exames médicos & 14 & 0 & 0 & 0 & 14 \\
\hline Locadora de automóveis & 47 & 2 & 4 & 0 & 53 \\
\hline Locadora de imóveis & 13 & 1 & 0 & 0 & 14 \\
\hline $\begin{array}{l}\text { Loja de artigos para saúde e } \\
\text { cuidados pessoais }\end{array}$ & 1 & 0 & 0 & 0 & 1 \\
\hline Loja de departamentos & 7 & 0 & 0 & 0 & 7 \\
\hline Mineração de metais & 12 & 0 & 0 & 0 & 12 \\
\hline Outras indústrias da recreação & 1 & 1 & 0 & 1 & 3 \\
\hline Saúde & 2 & 0 & 0 & 0 & 2 \\
\hline Seguradora & 10 & 2 & 0 & 0 & 12 \\
\hline Serviços de apoio a empresas & 2 & 0 & 0 & 0 & 2 \\
\hline $\begin{array}{l}\text { Serviços de engenharia e } \\
\text { arquitetura }\end{array}$ & 4 & 0 & 0 & 0 & 4 \\
\hline Tecelagens & 1 & 0 & 0 & 0 & 1 \\
\hline Telecomunicações & 14 & 2 & 0 & 0 & 16 \\
\hline Transporte & 77 & 18 & 1 & 12 & 108 \\
\hline TOTAL & 344 & 45 & 20 & 25 & 434 \\
\hline
\end{tabular}

Os dados na tabela 6 sugerem que as cláusulas de pagamento são as mais utilizadas pelas empresas do setor de transporte e energia elétrica. Como estes setores são altamente regulados e possuem o compromisso de expansão e investimentos em infraestrutura, justifica-se então, a presença de covenants em suas emissões de debêntures.

Por fim, para proceder a análise da presença dos covenants em emissões de empresas pertencentes a algum nível de Governança Corporativa, primeiro identificou-se a quais empresas possuíam classificação de boas práticas de Governança Corporativa e em seguida os covenants foram classificados segundo a tipologia de Smith et al. (1979).

Em relação ao perfil das empresas emissoras de debêntures listadas na B3, verifica-se que dentre as 154 empresas, 46 possuem algum nível de Governança Corporativa, sendo predominante as empresas pertencente ao Novo Mercado, representando aproximadamente $70 \%$ das empresas pertencente a amostra das empresas que detinham algum nível de governança, portanto, pode-se dizer que as empresas que 
emitiram estes títulos nos últimos 10 anos possuem em algum nível diretrizes de boas práticas de governança. Inclusive, sendo os covenants um indicador de redução de assimetria informacional. Os dados referentes a relação entre os tipos de restrições e o nível de governabilidade corporativa das empresas analisadas neste estudo estão sumarizadas na Tabela 7.

Tabela 7: Relação do nível de Governança Corporativa com os grupos de cláusulas de covenants para o período de 2010 a 2018.

\begin{tabular}{|l|l|l|l|l|l|}
\hline $\begin{array}{c}\text { Nível de } \\
\text { Governança }\end{array}$ & \multicolumn{1}{|c|}{$\begin{array}{c}\text { Cláusulas sobre } \\
\text { pagamentos }\end{array}$} & $\begin{array}{c}\text { Cláusula sobre } \\
\text { ativos }\end{array}$ & $\begin{array}{c}\text { Cláusula sobre } \\
\text { financiamento }\end{array}$ & $\begin{array}{c}\text { Cláusula sobre } \\
\text { dividendos }\end{array}$ \\
\hline Nível 1 & 7 & 0 & 0 & 0 \\
\hline Nível 2 & 30 & 2 & 1 & 7 \\
\hline Novo Mercado & 146 & 11 & 3 & 34 \\
\hline Sem Governança & 7 & 1 & 2 & 6 \\
\hline Não informa & 125 & 25 & 14 & 1 \\
\hline TOTAL & $\mathbf{3 1 5}$ & $\mathbf{3 9}$ & $\mathbf{2 0}$ & $\mathbf{1}$ \\
\hline
\end{tabular}

O covenant mais presente é o da categoria 'clausula de pagamento', identificou-se 315 covenants, e novamente as empresas do novo mercado são aquelas mais dispuseram de cláusulas restritivas relacionadas ao pagamento. Foram 146 observações desta categoria. Percebe-se, portanto, que quanto maior o nível de Governança Corporativa, mais itens restritivos são informados pelas empresas quando emitem títulos de dívida. Estes resultados corroboram com a literatura sobre conflito de agência e de que os covenants possuem conteúdo informacional. Adicionalmente, destaca-se as observações referente as condições de pagamento parecem ser aqueles mais úteis para informar aos credores sobre as condições de solvência da empresa.

No que concerne a associação entre os covenants e o nível de Governança Corporativa identificouse que as empresas classificas no Novo Mercado tem informado mais cláusulas restritivas em suas emissões de debêntures do que empresas pertencentes aos outros níveis de Governança Corporativa e as empresas que não possuem algum nível de governança. Foram identificados 184 covenants nas empresas do novo mercado de um total de 240 amostras. Ademais, uma das razões pela qual houve uma grande quantidade de covenants nas empresas que não informam o nível de governança se deve ao fato da necessidade de oferecerem mais garantias para o debenturista em virtude da falta de informações acerca da sua administração interna e das suas práticas.

\section{CONCLUSÕES}

O presente trabalho teve como objetivo identificar as cláusulas mais presentes nas emissões de debêntures e suas relações com o volume de emissão, vencimento e spread, bem como Nível de Governança Corporativa e setores de atuação das empresas, no período entre 2010 e 2018. Para este fim foi necessário, na coleta de dados, identificar as empresas brasileiras que emitiram debêntures no período de 2010 a 2018 e, em seguida, identificar e classificar os covenants presentes nas respectivas emissões. Por meio da contagem de frequência foi possível identificar as cláusulas restritivas mais presente nos contratos dos títulos e, por fim, buscou compreender como os covenants podem ser associados com as características das debêntures e das empresas, por meio de tabelas de frequência cruzadas e distribuição de frequência. 
Dentre os resultados encontrados se destaca que foram emitidas 220 debêntures para o período em análise, sendo os anos de 2017 e 2018 com maior incidência, totalizando 38,64\% das emissões dos períodos, um dos motivos que justificam esse volume de captação de recursos via debênture é o momento de recuperação da crise financeira e do crescimento da economia brasileira. Destaca-se também que os covenants de Dívida Líquida sobre EBITDA e Dívida sobre EBITDA, EBITDA sobre Despesa Financeira são os mais presentes nas emissões dos títulos. Estes somados representam $45 \%$ das cláusulas restritivas presentes nas emissões. Desta forma, a categoria de covenant mais presente é aquele referente aos pagamentos. Isto permite inferir que esta categoria pode se configurar como a mais relevante no tocante a assimetria informacional e desempenho da organização para honrar com o compromisso junto aos debenturistas.

Em relação a análise por setor percebeu-se que as empresas do setor de energia, saneamento e transporte foram aquelas que mais emitiram títulos. Essa prática é justificada pela isenção de imposto para as emissões de debêntures incentivadas e pela necessidade de investimento e expansão destes setores, como sugerem Sheng et al. (2005) e Aguiar (2012).

Por fim, quanto a associação dos covenants com os níveis de Governança Corporativa identificou-se que as emissões de empresas pertencente ao Novo Mercado são aquelas que contém mais restrições nas categoria de clausula de pagamento, permitindo inferir que essa categoria por possuir intima relação com a capacidade das empresas honrarem suas dívidas mediante a capacidade de gerar caixa e ser a mais presente é aquela que traz mais conteúdo informacional a respeito do desempenho da empresa e de garantias que os credores terão seus recebimentos.

Ante o exposto convém destacar que os covenants assumem importante papel nos contratos de dívidas uma vez que buscam muito mais a credibilidade do devedor, agindo diferente das garantias reais ou pessoais disponíveis no mercado, por exemplo, as garantias hipotecárias, pignoratícias ou fidejussórias. Além disto, Mello (2015) atribui a importância destas cláusulas dado que existem situações em que garantias tradicionais não são suficientes para promover negócios e assegurar o pagamento das dívidas.

O presente estudo converge parcialmente com os achados de Garleanu et al. (2009), uma vez que estes citam que as condições mais utilizadas para a montagem das cláusulas restritivas são baseadas sobre o patrimônio líquido da empresa, capital de giro, alavancagem, cobertura de juros, e fluxo de caixa, e envolvem restrições à emissão de dívida, o pagamento de dividendos e investimentos, ou impõem ações como a aceleração dos pagamentos da dívida.

Por fim, os resultados encontrados nesta pesquisa convergem com Armstrong (2010), dado que os credores buscam informações que lhes garantam o recebimento e a viabilidade das garantias dos empréstimos e nesse sentido foram evidenciados que empresas adotam majoritariamente os covenants de Dívida Líquida sobre EBITDA e Dívida sobre EBITDA, EBITDA sobre Despesa Financeira como medidas de garantia em seus contratos de dívida.

\section{REFERÊNCIAS}


ASSAF NETO, A.. Finanças corporativas e valor. 3 ed. São Paulo: Atlas, 2007.

ANBIMA. Associação Brasileira das Entidades dos Mercados Financeiro e de Capitais. Guia Anbima de orientação para escrituras de debentures. ANBIMA, 2014.

ARMSTRONG, C. S.; BARTH, M. E.; JAGOLINZER, A. D.; RIEDL, E. J.. Market reaction to the adoption of IFRS in Europe. The accounting Review, v.85, n.1, p.31-61, 2010.

BEIRUTH, A. X.; FÁVERO, L. P. L.. Um Ensaio Sobre a Adoção das International Financial Reporting Standards em Covenants Contratuais. Revista de Finanças Aplicadas, v.7, n.1, p.1-22, 2016.

BORGES, L. F. X.. Covenants: instrumento de garantia em Project Finance. Revista BNDES, Rio de Janeiro, v.1, n.11, 1999.

COELHO, C. U. F.; DIAS, A. M.. Valor justo de debêntures sem preços de referência no mercado: uma proposta metodológica de mensuração. Revista Ambiente Contábil, Rio Grande do Norte, v.9, n.1, p.56-76, 2017.

CHRISTENSEN, H. B.; NIKOLAEV, V. V.. Capital versus performance covenants in debt contracts. Journal of Accounting Research, v.50, n.1, p.75-116, 2012

GIACOMINI, B. H.; SHENG, H. H.. O impacto da liquidez nos retornos esperados das debêntures brasileiras. Revista de Administração da USP, São Paulo, v.48, n.1, p.80-97, 2013.

GARLEANU, N.; ZWIEBEL, J.. Design and renegotiation of debt covenants. Review of Financial Studies, v.22, n.2, p.749-781, 2009.
JENSEN, M.; MECKLING, W.. Theory of the firm: managerial behavior, agency costs and ownership structure. Journal of Financial Economics, v.3, n.4, p.305-360, 1976.

MATHER, P.; PEIRSON, G.. Financial covenants in the markets for public and private debt. Accounting and Finance, v.46, n.2, p.285-307, 2006.

NEIS, D. W.; MARAGNO, L. M. D.; BORBA, J. A.. Análise dos principais tipos e características cos covenants nas empresas do Novo Mercado. In: ENCONTRO CARARINENSE DE ESTUDANTES DE CIENCIAS CONTÁBEIS, 14. Anais. ECECON, 2016

PERIN, M. S.; GLITZ, F. E.. Covenants em contratos de financiamento de longo prazo: uma perspectiva jurídica. RJLB, Lisboa, n.1, p.1375-1393, 2015.

SAITO, R; SHENG, H. H.; BANDEIRA, M. L.. Governança corporativa embutida nas escrituras de debêntures emitidas no Brasil. Revista de Administração da USP, v.42, n.3, p.280292, 2007.

SMITH, C.; WARNER, J.. On financial contracting: an analysis of bond covenants. Journal of Financial Economics, v.7, p.117-161, 1979

SHENG, H. H.; SAITO, R.. Determinantes de Spread das debêntures no mercado brasileiro. Revista de Administração da USP, v.40, n.2, p.193-205, 2005.

WATTS, R. L.; ZIMMERMAN, J. L.. Positive Accounting Theory. Upper Saddle River: Prentice Hall, 1986.

WATTS, R. L.; ZIMMERMAN, J. L.. Positive accounting theory: a ten year perspective. The Accounting Review, v.65, n.1, p.131-156, 1990.

A CBPC - Companhia Brasileira de Produção Científica (CNPJ: 11.221.422/0001-03) detém os direitos materiais desta publicação. Os direitos referem-se à publicação do trabalho em qualquer parte do mundo, incluindo os direitos às renovações, expansões e disseminações da contribuiç̃o, bem como outros direitos subsidiários. Todos os trabalhos publicados eletronicamente poderão posteriormente ser publicados em coletâneas impressas sob coordenação da Sustenere Publishing, da Companhia Brasileira de Produção Científica e seus parceiros autorizados. Os (as) autores (as) preservam os direitos autorais, mas não têm permissão para a publicação da contribuição em outro meio, impresso ou digital, em português ou em tradução. 